\title{
Patrón de exposición televisiva de jóvenes de preparatoria de la ciudad de Monterrey*
}

Yamille de la Garza Tecnológico de Monterrey, Campus Monterrey

Mundialmente se ha presentado un claro desbalance entre la cantidad de materiales extranjeros y nacionales transmitidos por las televisoras y se ha vuelto un tema de gran interés el impacto que esto pudiera tener en las identidades culturales de las naciones "receptoras". Sin embargo, un paso necesariamente anterior a cualquier afirmación referente a cambios y/o transformaciones en sentimientos y costumbres nacionales es el de conocer el patrón de exposición y las preferencias programáticas de la audiencia ante la información importada que se le ofrece. Adicionalmente, es importante saber cuáles son los factores que determinan y/o influencian sobre estos patrones y preferencias.

Recientes investigaciones del área de comunicación de masas han descrito y comentado un fenómeno que fue denominado para fines de este estudio como "Preferencia Nacional" (llamado por Wilkinson (1995) como "Mercado Cultural-Linguístico" y por Straubhaar (1993) como "Proximidad Cultural"). Este afirma que las audiencias tienen una inclinación hacia contenidos locales, nacionales, o en su defecto regionales (producciones de pases aledaños que comparten mismo idioma y, en algunos casos, ideosincrasia), por encima de los netamente extranjeros, no importando si la oferta de éstos últimos es mayor. Además, dichos análisis han expuesto que existe una relación entre las variables sexo y clase social y la manifestación de la "Preferencia Nacional". De acuerdo a estos estudios, el sexo masculino y aquellas personas pertenecientes a altas esferas socioeconómicas, tienen una tendencia mayor a la exposición de contenidos extranjeros.

* La autora agradece el apoyo para la realización de esta investigación al Dr. José Carlos Lozano, Ing. Javier Aldrete y Lic. Horacio Tijerina. 
Con el fin de aportar información que enriquezca el marco teórico de estudios de recepción relacionados con la "Preferencia Nacional", el presente trabajo se fijó cuatro preguntas de imvestigación: ¿cuál es el promedio de exposición a la programación extranjera ofrecida por televisión por parte de los jóvenes de preparatoria en la ciudad de Monterrey? ¿cómo se manifiesta la "Preferencia Nacional" en el grupo investigado? ¿cómo afecta la variable sexo para la exposición y preferencia? ¿cómo afecta la variable clase social para la exposición y preferencia?

\section{Oferta televisiva en la ciudad de Monterrey, México'}

La razón por la que se realizó la investigación en Monterrey es que, siendo la ciudad industrial más importante de México y estando tan cerca de los Estados Unidos, esta ciudad tiene un alto poder adquisitivo y recibe una gran cantidad de información del país vecino. Muchas empresas transnacionales han ubicado sus sedes en Monterrey al igual que un alto número de las empresas mexicanas más grandes. Esto ha provocado que Monterrey se comience a desarrollar como una ciudad cosmopolita, con una gran oferta de información no sólo financiera y artística, sino también de medios de comunicación.

Como ha sucedido en la mayoría de los países del mundo, según informan Rogers y Antola (1984), Varis (1984), Larsen (1990) y Sepstrup (1995), la oferta en los medios de comunicación en Monterrey se ha visto cargada de información extranjera, particularmente estadounidense. Específicamente, en referencia a la televisión, esto sucede tanto en el modo aéreo como en el de paga.

En la ciudad de Monterrey existen 9 canales de televisión aérea y dos compañías de televisión de paga que ofrecen sus servicios. El Canal 2 local de Monterrey ofrece programación local y nacional y rara vez, algún programa extranjero. El Canal 13 red nacional de Televisión Azteca combina programación extranjera y nacional. El Canal 5 XHGC de Televisa, 6 en la ciudad, transmite básicamente programas extranjeros, principalmente estadounidenses. TV-7 de Televisión Azteca produce noticieros y programas locales, transmite otros nacionales y también incluye materiales extranjeros muy exitosos. El Canal de las Estrellas, 2 de Televisa y 10 local, se compone de material nacional,

1 Toda la información anterior referente a canales y oferta de los mismos fue analizada con datos vigentes en 1996. 
destacando las famosas telenovelas mexicanas. El 12, canal local, produce programas regionales y repite algunos programas extranjeros, al igual que el Canal 2. El Canal 22, nacional de televisa y el 34, canal local, ofrecen películas y series mexicanas o extranjeras. Los programas y cualquier otro material cultural se transmiten por el Canal 28, pertenenciente al Estado de Nuevo León.

En cuanto a la televisión de paga, la empresa Cablevisión ofrece alrededor de 41 canales de televisión, mismos que ofrecen videos en español y/o en inglés; deportes en español o inglés; programas y películas mexicanas y series y películas extranjeras en idioma original o doblado al español. Hay también un canal en alemán y el canal TVE de España. Multivisión ofrece 24 canales, de los cuales algunos contienen programación mexicana pero la mayoría son dedicados a películas y series norteamericanas, algunas dobladas y otras en su idioma original.

Ante este tipo oferta, altamente cargada de información extranjera, fue de gran interés conocer si los jóvenes de preparatoria inclinaban sus preferencias por contenidos extranjeros o nacionales. Estos datos podrían enriquecer el panorama hasta ahora establecido en relación a la "Preferencia Nacional" en los estudios de comunicación de masas a nivel internacional.

\section{"Preferencia Nacional": una opción ante el desbalance de oferta}

Ya que ha sido afirmado que existe una fuerte cantidad de importación de programación extranjera, especialmente entretenimiento norteamericano, no solamente por parte de la TV mexicana (Sánchez Ruiz, 1992), sino también de las televisoras de la mayoría de los pases del mundo (Rogers y Antola, 1984, Varis, 1984, Larsen, 1990 y Sepstrup, 1995), es importante tomar el punto de vista de la audiencia y analizar cuáles son los patrones de exposición de la misma. Aúny cuando existe esta amplia oferta de productos culturales extranjeros, se requiere saber cuáles son las preferencias de los televidentes ante los mismos. Otros estudios que hayan dedicado esfuerzos a dar respuesta a este cuestionamiento, pueden servir de orientación en la explicación de la "Preferencia Nacional".

\section{Importación versus preferencias}

Debido a que la razón de la preocupación existente por la presencia de programación extranjera, en particular la norteamericana, es la influencia que pueda ejercer sobre 
Patrón de exposición televisiva de jóvenes ...

los paises consumidores, el fenómeno de la "Preferencia Nacional" es sumamente importante.

Rogers y Antola descubrieron durante su estudio de cinco pases latinos, que la teleaudiencia tiene, generalmente, una preferencia del orden siguiente: primero, programas producidos localmente; segundo, producciones importadas de otras áreas de la región y, tercero, programas importados de los Estados Unidos o de otras partes del mundo (Rogers y Antola, 1984).

Algunas de las razones para que esto suceda asi es debido a las barreras naturales que la audiencia tiene hacia el material importado. La barrera del lenguaje hace que la gente prefiera ver, en general, programas producidos en su propio idioma antes que en otro. Otra barrera que favorece la "Preferencia Nacional" es la cultura misma. Los valores y las creencias del teleauditorio impactan sobre su sentimiento de agrado o desagrado hacia un tipo de producto. Además, esto facilita o impide la comprensión del programa; en ocasiones un producto cultural muy exitoso en cierto lugar, fracasa en otro debido a la fuerte diferencia cultural.

Wilkinson (1995) ofrece una explicación detallada sobre la barrera del lenguaje y la cultura en relación al flujo y preferencias de programación, lo que él ha denominado como "Mercado Cultural-Linguístico". El investigador afirma que el éxito de un programa está determinado por tres elementos que componen este concepto. El primero, la cultura, es identificada como "la semejanza en raíces étnicas; historia política, económica y social; lenguajes; religión y valores" (Wilkinson, 1995: 2). En Latinoamérica, en particular, hay una cultura compartida, lo que facilita el intercambio de programación y su atracción en las audiencias.

El idioma es el segundo factor de importancia en el éxito de algunos programas. Wilkinson considera que aún el tipo de acento en una misma lengua (en el caso de Latinoamérica el español) puede causar variaciones en el atractivo de una producción.

El intercambio y los intereses económicos de la industria componen el tercer elemento del "Mercado Cultural-Linguístico". Las condiciones del mercado y las estrategias competitivas determinan, en parte, las decisiones de los productores y programadores de qué programas producir o importar. Según la investigación de Wilkinson, en el momento de elegir estas personas consideran tanto el precio del producto como la cercana cultural con la audiencia local.

Esto explica lo que se define como "Preferencia Nacional": "la tendencia del público a gustar más lo 'hecho en casa' por encima de la programación producida en el extranjero, sobre todo si se puede escoger entre uno y otro dentro de un mismo género, aún y cuando 
se tenga acceso a diversas tecnologías. Por Nacional se entiende, en este contexto, el proceso de ir escogiendo de lo más cercano (en relación a la cultura, lenguaje, historia, religión, etc.) hacia lo más lejano" (De la Garza, 1996).

Otro estudio que ofrece información sobre la "Preferencia Nacional" es el de José Carlos Lozano. El investigador realizó un estudio con alumnos de secundaria de la Frontera Norte y encontró que en Nuevo Laredo, ciudad fronteriza con el Estado de Texas, los jóvenes prefieren por mucho la programación nacional (Lozano, 1994). A pesar de que los jóvenes mostraron una alta exposición a los medios, sus preferencias de canales y programas mostraron que su tendencia era hacia lo producido nacionalmente o en regiones latinoamericanas.

En cuanto a preferencias programáticas, el estudio de Lozano arrojó que de los 33 programas que los encuestados solan ver, los primeros 16 eran producidos en nuestro país por Televisa o por Telemundo en Miami, con conductores hispanos (Lozano, 1994: 230). Rogers afirma, por su parte, que en 1981 solamente 4 de los 50 programas de mayor sintonía en los países de su estudio eran norteamericanos y ninguno de éstos sobrepasó el séptimo puesto entre los diez primeros (cfr. Malagamba, 1986 en Lozano, 1994).

Straubhaar (1993) afirma que en Sao Paulo se presentó un decremento en las horas audiencia de programas norteamericanos de un $47 \%$ en 1971 , hacia un $29 \%$ en 1983 , ya que se dio una marcada preferencia de la teleaudiencia por la programación nacional como telenovelas, programas de variedades, noticieros, y programas musicales y de comedia. Después de 1983 , entre $66 \%$ y $71 \%$ de las horas audiencia de esta ciudad se dedicaron a programas brasileños. El autor establece que esta "Preferencia Nacional" se debe a lo que él denomina Proximidad Cultural: "inclinación de las audiencias hacia lo producido nacional o localmente, lo cual es más cercano y refuerza más las identidades tradicionales basadas en lo regional, lo étnico, el dialecto-idioma, lo religioso y otros elementos" (Ibid: 92).

En Monterrey, Rocío Díaz (1995) confirmó con alumnos de secundaria la preferencia por lo local: once de los 17 programas más mencionados por los estudiantes eran mexicanos, sólo 6 eran extranjeros. El canal preferido por estos jóvenes de secundaria era el Canal 2 de Televisa, con un 79.4\%. El periódico El Norte, también en esta ciudad, publicó en 1993 una investigación realizada por ellos mismos, en la que se afirmó que el canal de televisión preferido de los regiomontanos era el Canal 2 de las Estrellas (EI Norte, 1993: 8E).

En su estudio de la televisión y los tapatios, Aceves (1991) descubrió en 1989 que el canal preferido en Guadalajara era el Canal 2 de Televisa con el 52\% del total de la 
Patrón de exposición televisiva de jóvenes ...

muestra. Si bien la oferta programática del Canal de las Estrellas era distinta a la actual, se compona de secciones de información y entretenimiento (básicamente telenovelas y programas cómicos) producidos en nuestro país. Esto confirma, por ende, que la audiencia de esta ciudad preferia exponerse a contenidos nacionales. Los resultados de Lozano son similares a los de Aceves y Díaz: el canal preferido de los jóvenes de Nuevo Laredo era el Canal 11, repetidor del Canal 2 de Televisa (Lozano, 1994).

En el estado francés Quebec, en Canadá, Roger de la Garde (1993) realizó una investigación cuyos resultados son similares a los anteriores. Después de analizar las preferencias de los diez canales de televisión que la empresa de ratings "Bureau of Broadcast Measurement, Autumn Report 1987" reportó, el investigador afirma que las audiencias francoparlantes prefirieron la televisión Quebecua por encima de la producida en Canadá o la importada de Estados Unidos en todas las categorías de programación. En Quebec, el 88\% de tiempo que se ve televisión, es dedicado a programas Quebecuas.

Al dividir la audiencia por edades, De la Garde confirmó que todas mostraron preferencia por lo regional, aunque reporta que del total, los jóvenes adolescentes "tienen el consumo más alto de productos estadounidenses, tanto originales (13.2\%) como doblados (10.1\%)" (De la Garde, 1993: 42). Sin embargo, el promedio de horas por semana de televisión visto por los jóvenes era como sigue: 13.38 horas de programas domésticos (Quebecua); 4.78 horas de productos importados de los Estados Unidos y 1 hora de importados de 'otras partes'. Lo que confirma que, a pesar de que los jóvenes fueron quienes más consumieron contenidos extranjeros, el porcentaje de exposición a materiales domésticos es mayor (De la Garde, 1993). Este dato es una referencia importante ya que la presente investigación analiza los patrones de consumo televisivo de muchachos adolescentes de preparatoria.

Confirmando este contraste entre oferta y consumo, en 1991 Preben Sepstrup y un grupo de investigadores estudiaron cinco países europeos: Bulgaria, Hungría, Italia, Suecia y los Países Bajos con el fin de dar seguimiento a las investigaciones que realizara anteriormente Tapio Varis, comparando los contenidos ofrecidos y los consumidos por las audiencias.

Los resultados muestran que a pesar de que los canales de los cinco países analizados ofrecen un alto porcentaje de productos extranjeros, el consumo era generalmente más bajo. El investigador concluye que el consumo "es más importante cuando la oferta de canales de paga y satelitales es considerable" (Sepstrup, 1995: 5).

A pesar de que a través de los estudios anteriormente expuestos queda tan clara la preferencia de las audiencias hacia lo nacional o regional, se han encontrado dos 
variables que incrementan o decrementan el grado de preferencia: el sexo y la clase socioeconómica.

\section{Clase social y sexo: factores determinantes}

Profundizando en el estudio del fenómeno de la "Preferencia Nacional", como se verá a continuación, se ha concluído que la clase económica y social y el sexo tienden a determinar los gustos de la audiencia.

Algunos estudios han detectado que las clases altas se exponen más a la programación norteamericana en comparación con sus contrapartes de clase media o baja (cfr. Lozano, 1994; Bustamante en Lozano, 1994; Straubhaar, 1993; Daz, 1995). Lozano afirma en relación a lo anterior que "a mayor clase social, mayor predilección por la cultura estadounidense" (Lozano, 1994: 234) mientras que Straubhaar afirma que hay "una notoria mayor receptividad hacia la cultura local y nacional por parte de las 'clases populares', esto es, la clase baja-media, la clase trabajadora y los pobres" (Straubhaar, 1993: 92).

De hecho, Straubhaar afirma que el nivel de escolaridad afecta las preferencias de las audiencias. El investigador reporta que en un estudio realizado en 1990 en la ciudad de Sao Paulo, se comprobó que los programas norteamericanos y las películas internacionales tendieron a ser fuertemente preferidos entre los que tienen mayor escolaridad. En contraste, la preferencia por los shows nacionales de variedades y comedias mexicanas fue más fuerte entre los sectores con menos escolaridad. Igualmente se comportaron las audiencias en Santo Domingo donde, aunque existía una preferencia general por la programación dominicana, en las clases populares destacó la atracción por programas regionales, tales como comedias mexicanas y telenovelas. Esto a diferencia de las élites, quienes mostraban una mayor preferencia por lo extranjero en comparación con sus contrapartes de clase inferior (Straubhaar, 1993).

También los alumnos de secundaria de Monterrey tenían una preferencia por programación de acuerdo a su clase social y sexo. Rocío Díaz reporta que, aunque para todos el Canal 2 de Televisa era el favorito, la clase baja lo prefería con un porcentaje mayor en contraste con la clase media y la alta, mientras que las mujeres preferían exponerse a este canal más que los hombres (Díaz, 1995). Este hallazgo es equivalente al que encontró Aceves en Guadalajara, quien afirma que el canal favorito de toda clase social era el Canal 2, aunque existía una mayor preferencia por parte de las mujeres a exponerse a los contenidos del mismo (Aceves, 1991). 
Patrón de exposición televisiva de jóvenes ...

No hay mucha diferencia con referencia a la televisión por cable. Díaz informa que la clase alta fue la que reportó tener mayor acceso y exposición a canales y contenidos extranjeros respectivamente. En cuanto a sexo, el $52.6 \%$ de los hombres encuestados sintonizaba todos los días y con frecuencia estaciones de los Estados Unidos, mientras que sólo el $37.8 \%$ de las mujeres lo hacían. Las mujeres se exponían más a canales musicales, siendo el favorito D99, producido localmente aunque con contenidos nacionales y extranjeros; los hombres preferian estaciones de películas tales como Fox y Cinema Golden Choice, de origen norteamericano.

En Quebec, De la Garde también pudo constatar que las mujeres tienen una preferencia levemente mayor por los contenidos nacionales o regionales. En su estudio, las mujeres consumían un promedio de horas por semana de programas domésticos de 22.2, a diferencia de los hombres, quienes reportaron 15.91 horas (De la Garde, 1993).

En cuanto a ratings, solamente Díaz relaciona preferencias programáticas con sexo. La investigadora encontró que sí existe una correlación entre ambas variables, afirmando que los hombres de secundaria en Monterrey tenían una mayor preferencia por los programas extranjeros en comparación a sus compañeras féminas. Los primeros programas que las muchachas preferían eran todos mexicanos, la mayoría telenovelas del Canal 2 de Televisa. Los hombres, en cambio, prefirieron igual programas mexicanos que extranjeros.

En Nuevo Laredo, Lozano encontró que aunque la clase social no propiciaba diferencias en la frecuencia con la que los estudiantes veían programación mexicana, sí era importante para la exposición de contenidos norteamericanos. "Los estudiantes de clase alta veían más programas estadounidenses .... que los de la clase media o baja" (Lozano, 1994: 234). Esta exposición a programación extranjera se dio en aquellos alumnos que estaban suscritos al sistema de cable o poseían una antena parabólica.

Esto no significa, sin embargo, que los televidentes de clase alta que se muestran expuestos a programación norteamericana, experimenten en contraste un menosprecio por lo propio. En la investigación de Lozano, los estudiantes de clase social superior, al igual que los de clase media y baja, tuvieron una gran preferencia por lo producido en México. El autor dice a este respecto que "Hay que aclarar... que los jóvenes de clase alta -aunque proporcionalmente veían más series estadounidenses que los dos grupos restantes- veían significativamente más programas mexicanos que estadounidenses" (Ibid). Esta conclusión es importante ya que, si bien los alumnos de clase alta y los hombres muestran una ligera preferencia hacia lo extranjero en comparación a sus contrapartes, esto no debilita la marcada preferencia por lo nacional que los anteriores estudios reflejan. 
Ya que las investigaciones que se han realizado en relación a las preferencias de las audiencias arrojan que, en efecto, hay un gusto e inclinación de las mismas hacia aquello que apele y refleje sus más cercanos sentimientos y vivencias, y que la clase social y el sexo parecen provocar una diferencia en el grado de preferencia hacia contenidos nacionales o extranjeros, el presente estudio se enfocó en conocer cuáles eran las preferencias programáticas de los jóvenes regiomontanos y cómo se relacionaban el sexo y la clase social con estos gustos.

\section{Método}

La investigación se llevó a cabo de enero a mayo de 1996, a través de la aplicación de una encuesta a jóvenes de preparatoria de Monterrey y su área conurbada. El objetivo de la encuesta fue conocer cuáles eran las preferencias de los estudiantes en relación a los canales de televisión aérea y de paga y los programas ofrecidos por los mismos.

Para elegir la muestra de esta investigación, se siguió un proceso polietápico. Considerando que, según el Reporte de la Secretaría de Educación Pública en el Estado de Nuevo León 1994-1995, el total de preparatorias en turnos matutino, vespertino, nocturno y discontinuo ${ }^{2}$ era de 89 , se consideró apropiado escoger 10 preparatorias como muestra. Ya que una de las variables importantes de este estudio es la clase socioeconómica, se tomó la decisión de escoger al azar 5 preparatorias del sector privado y $5 \mathrm{del}$ sector público. Para ello, el siguiente paso fue dividir el listado de instituciones de acuerdo a su condición de privada o pública.

También era importante que las preparatorias con mayor alumnado recibieran oportunidades mayores de participar, por lo que cada una fue seleccionada de modo aleatorio y ponderado de la siguiente manera: se otorgó un número a cada escuela por cada cien alumnos; el listado final estuvo entonces entre los rangos del 1 al 405 en el caso de preparatorias públicas y del 406 al 537 en preparatorias privadas. Los números finales fueron elegidos al azar.

Ya que el universo (N) era igual a 49,596 estudiantes de preparatoria, el total de encuestas a aplicar era de 381 . Este número se obtuvo de acuerdo a la fórmula de Krejcie

2. Debido a que los alumnos inscritos en turnos discontinuos o noctumos no tienen las mismas características de edad ni de condición laboral que aquellos estudiantes de turnos matutinos o vespertinos, se decidió no tomarlas en cuenta como parte de la muestra, aunque estuvieron participando dentro del listado. 
Patrón de exposición televisiva de jóvenes ...

(1970), que afirma que la proporción $p$ estará entre un .05 de la proporción de la población $P$ con un 95 por ciento de confianza.

Estas 381 encuestas se repartieron proporcionalmente entre las 10 preparatorias seleccionadas de acuerdo a su cantidad de alumnos. Para llevar a cabo esta operación, se sumó el total de alumnos de las 10 instituciones para, a través de una regla de tres simple, obtener el número de entrevistados por escuela.

El siguiente paso fue realizar el sorteo aleatorio de alumnos y/o grupos dentro de las preparatorias a encuestar. Para ello, se decidió escoger al azar seis grupos de cada institución, exceptuando aquellas en las que solamente se debian aplicar 3 encuestas. Se dividió el número de encuestas de cada preparatoria entre estos seis grupos, y ese fue el número de estudiantes escogidos para cada grupo al azar. Para realizar este sorteo al azar, las preparatorias proporcionaron una copia de sus listados de grupos.

En el caso de las dos preparatorias más grandes, una privada y otra pública, en las que se debía aplicar el mayor número de encuestas, se decidió realizar un censo a los seis grupos escogidos al azar en el caso de la primera y cuatro en el caso de la segunda. Finalmente, el total de estudiantes encuestados fue $\mathbf{4 4 2}$.

\section{Resultados}

\section{Datos generales}

La aplicación de las 442 encuestas en las 10 preparatorias de Monterrey y su área conurbada se dividió entre cinco preparatorias privadas y cinco públicas, como ya ha sido mencionado. El 43.7\% de las encuestas pertenecieron a alumnos de preparatorias privadas y el $56.6 \%$ restante a estudiantes de preparatorias públicas. Del total que contestaron la encuesta, 229 eran mujeres y 211 hombres; $21.9 \%$ pertenecian a la clase alta, $50.1 \%$ a la clase media y $28 \%$ a la clase baja.

\section{Acceso a TV aérea y de paga}

Dentro del cuestionario, se preguntó a los alumnos si tenían televisión. La respuesta fue casi unánime: el $\mathbf{9 9 . 8 \%}$ tenía televisión en su casa, lo que significa que sólo una persona no poseía TV. 
Respecto al acceso a la TV de paga, un altísimo porcentaje de los estudiantes tenía alguno de estos sistemas de transmisión: $61.2 \%$. Esto asombra si se compara con el estudio de Lozano (1994) quien reporta un $36 \%$ de estudiantes en Nuevo Laredo, que poseían cable o parabólica en 1988; con Díaz (1995) en Monterrey, quien afirma que el $37.6 \%$ de su muestra tenían en casa cualquiera de estos sistemas en 1994 y con Greenberg y Buselle (1993) quienes afirmaron que en su investigación en la Ciudad de México, 40\% de los encuestados tenía algún tipo de televisión de paga en 1991. Si no se debe a características peculiares de la muestra, este porcentaje podría indicar que el acceso a este tipo de sistemas está aumentando entre la población y que esto está facilitando la exposición a programación extranjera, ya que la antena parabólica, Cablevisión y Multivisión ofrecen un alto porcentaje de programación norteamericana en idioma original o doblada. Rocío Díaz (1995: 48) reporta que la televisión de paga ofrecía un total de 3,033 horas semanales de programación norteamericana en contra de 998 horas de material de procedencia nacional.

Específicamente, el $40.6 \%$ del total tenía contratado el servicio de la compañía Cablevisión; el $11.1 \%$ de los preparatorianos veían Multivisión; un 2.5\% tenía ambos sistemas y un $7.1 \%$ tenía solamente parabólica. No se contabilizó a aquellos que además de tener acceso a cualquiera de los dos sistemas de paga tenían antena.

En general, la mayoría de los muchachos de preparatoria gustaban ver televisión durante las tardes y las noches, alrededor de 4 horas diarias. Este alto número de exposición al medio no parece ser ajeno a otras investigaciones. Rocío Díaz (1995) encontró igualmente que los jovencitos de secundaria veían 5 horas de TV al día también durante las tardes y las noches. Greenberg y Buselle reportaron que en la Ciudad de México, los niños veían 6 horas diarias mientras que los de Sao Paulo otras 4.

Ya que se comprueba la gran cantidad de tiempo que pasan los niños y jóvenes frente a la televisión, se vuelve importantísimo conocer a qué tipo de contenidos se están exponiendo, cuál es el origen de los mismos y cuál o cuáles podrían ser la consecuencias.

\section{Canal aéreo favorito}

Los estudios realizados en México en relación a preferencia de canales de televisión (Aceves, 1991, Lozano, 1994 y Díaz, 1995) han arrojado que el Canal 2 de Televisa es el favorito de las audiencias. En el cuestionario aplicado en este estudio se pregunta directamente a los estudiantes cuál es su canal aéreo favorito. Los resultados son 
Patrón de exposición televisiva de jóvenes ...

contundentes: el favorito es el Canal 2, el de las Estrellas, con un 43.6\%. Esto es relevante ya que la programación de este canal es casi cien por ciento nacional, producida por Televisa y no se enfoca abiertamente a un público juvenil, como sí lo hacen el Canal 5 de Televisa y el 7 de TV-Azteca.

El segundo canal favorito era el canal 7 de Televisión Azteca con un 28.3\%. Eśto marca una diferencia en relación a investigaciones anteriores, ya que Díaz y Aceves reportaion que en sus estudios en Monterrey y Guadalajara la estación favorita en segundo lugar era XHGC Canal 5. Esta estación estuvo en tercer lugar, en efecto, pero con un porcentaje de $18.3 \%$. En cuanto a contenido de ambas transmisoras, se comentó anteriormente queXHGC ofrece un gran porcentaje de programas extranjeros; en contraste, aunque TV-7 está ofreciendo en su horario estelar programas norteamericanos muy gustados por los jóvenes (como se analizará más adelante), también incluye otros tantos producidos por la empresa Televisión Azteca o importados de la Región.

\section{Programas de televisión aérea favoritos}

Después de conocer cuál era el canal favorito, también se preguntó a los estudiantes cuáles eran sus programas favoritos de la televisión aérea por orden de importancia.

No tenemos que observar detenidamente el Cuadro l para notar que el balance entre programas extranjeros y mexicanos es ligeramente inclinado hacia contenidos nacionales. También es fácilmente observable que los dos programas favoritos son Los Simpsons y El Príncipe del Rap con un porcentaje mucho más alto que los obtenidos por los programas que les siguen.

Si hacemos una sumatoria, veremos que se mencionaron más programas mexicanos que extranjeros: 10 nacionales y 7 estadounidenses. Si esto se compara con el reporte de Rogers (1984), quien afirmó que de los 50 programas de mayor sintonía en los países que él analizó, sólo 4 eran norteamericanos y ninguno sobrepasaba el séptimo puesto entre los diez primeros, estos hallazgos podrian resultar preocupantes. También Lozano reportó un promedio mucho mayor de programas mexicanos que extranjeros, diciendo que de los primeros 33 que obtuvieron más menciones, los primeros 16 eran nacionales o bien regionales.

Sin embargo, si comparamos los resultados recientemente expuestos con los de Rocio Díaz y los adolescentes de secundaria, veremos que los números son muy similares. De los 17 más mencionados, 11 eran mexicanos y 6 americanos. Esto podría indicar que en 
la ciudad de Monterrey los adolescentes se exponen en un grado ligeramente mayor a contenidos extranjeros en relación a otros ubicados en Nuevo Laredo, donde Lozano realizó su estudio.

Por otra parte, es interesante cuestionarnos cuáles podrían ser algunas razones por las cuales Los Simpsons y El Príncipe del Rap fueron los más mencionados por los muchachos entrevistados. ¿Será porque no hay otras opciones parecidas que se ofrezcan en México? Àporque son programas juveniles? ¿existirá alguna identificación con las situaciones que plantean los personajes principales?

Anteriormente se mencionó que una de las razones para que exista la "Preferencia Nacional" es que el gusto por lo propio es debido a la identificación que propicia aquel programa hecho en "casa" por encima del que no representa realidades asibles o cercanas para el receptor. Habría que analizar entonces si en este contexto particular Los Simpsons y el Principe del Rap están transmitiendo información que pareciera cercana a los jóvenes que están gustando de éstos programas y cuáles podrían ser los elementos de identificación. Para ello se requeriría de investigación a profundidad, del tipo cualitativo.

Existe poca oferta de programas provenientes de Lationamérica, tales como telenovelas, series cómicas y otros programas de variedades, que no fueron significativamente mencionados por los estudiantes. La preferencia de ellos se inclinó más hacia lo producido en México. Esto podría deberse a que el género (que ha sido demostrado por Straubhaar (1993) como un factor que inclina las preferencias hacia lo nacional o lo extranjero según sea el caso) representado por estos programas es fuerte nacionalmente, como la telenovela, y por ello no causa tanta atracción aún y cuando es proveniente de la región.

\section{Programas de televisión de paga favoritos}

Es bien conocido que la mayoría de las empresas de televisión de paga ofrecen un porcentaje mayor de contenidos extranjeros. Por lo tanto, no es de extrañarse que los alumnos al ser preguntados "¿Cuáles son tus programas favoritos transmitidos por TV de paga?" hayan mencionado 15 programas y/o canales americanos y sólo 5 mexicanos. Curiosamente, los encuestados afirmaron gustar de canales de Cablevisión o Multivisión en lugar de mencionar específicamente programas, tal y como se les solicitó. Esto podría sugerir que el género o el concepto ha reemplazado en cierta medida el gusto por mensajes específicos y/o que la mercadotecnia de estos canales es muy buena. De los primeros 12 canales favoritos, 9 eran norteamericanos y sólo 3 mexicanos. La procedencia de los 8 
Patrón de exposición televisiva de jóvenes ...

programas mencionados también era desbalanceada: 6 eran americanos y únicamente 2 mexicanos. Esta información se presenta en el Cuadro 2.

Al igual que en los programas favoritos por TV aérea, Los Simpsons tuvo la mayor preferencia de la audiencia. Le siguió el canal de videos D99, que ofrece canciones rock y pop en inglés y español. En tercer lugar en predilección estuvo el programa norteamericano Beverly Hills 90210 seguido del canal Cinema Golden Choice, quien se dedica a presentar películas norteamericanas. Tele Hit y "El Calabozo" son mexicanos; el primero un canal de videos de cualquier nacionalidad pero en español y el segundo un programa de entretenimiento producido por Televisa. Entre el resto de los primeros diez favoritos se encuentran tres canales de televisión americanos y un programa de la misma procedencia.

Los resultados en las secciones de programas favoritos de televisión aérea y de paga muestran que, mientras que en promedio los estudiantes ven más programas mexicanos por TV aérea, no así en lo referente a la televisión de paga. Es necesario, por tanto, cuestionarnos cuál de las dos formas de televisión ven más aquellos jóvenes que tienen acceso a ambos sistemas. Si existe una mayor exposición a Cablevisión o Multivisión y lo más visto en ambos es canales y programas extranjeros, por lógica la programación con mayor audiencia es la importada.

Con el fin de clarificar lo anteriormente expuesto, se presenta a continuación la información referente a la frecuencia de exposición a canales de TV de paga para posteriormente contrastar las medias obtenidas en lo referente a éstos y la televisión aérea.

\section{Frecuencia de exposición a canales de televisión de paga}

Cuando los alumnos respondían que en su casa tenían contratados los servicios de las empresas Cablevisión o Multivisión se les preguntaba la frecuencia con que veían cada uno de los canales que ofrecen las mismas.

En términos generales, como puede verse en los Cuadros 3 y 4 , los canales de paga preferidos por los jóvenes regiomontanos de preparatoria fueron D99, Tele Hit, FOX, Cinema Golden Choice, Tele Uno, Multicinema y ESPN, ofreciendo una gran carga de programas, películas, videos, deportes y series extranjeros.

Sin embargo, es un contrapeso el notar que los canales vistos con mayor frecuencia son local (D99) y nacional (Tele Hit) cuyo contenido son videos en espaniol (provenientes de Latinoamérica o España) e inglés. Esto podría significar, por un lado, que los jóvenes gustan mucho de este tipo de programas de canciones dramatizadas y, por otro, que les 
agrada estar en contacto con conductores que ofrecen significados cercanos a su cultura e información relacionada con su entorno. Esto tendría que ser comprobado a través de estudios cualitativos que permitieran ofrecer mayor información sobre los gustos y preferencia de los estudiantes de preparatoria.

Es interesante destacar que, al igual que en la investigación de Díaz, los canales con programación cultural, mexicana y/o latinoamericana tuvieron muy poco éxito, tales como 9 y 11 de México, Teatro Alameda, Super Estelar, Ritmo y Son, Cine Mexicano por Cable, Arts y Sur. Esto podría significar por un lado que, aún y cuando hay algunas opciones en español, los estudiantes están prefiriendo programas extranjeros. Por otro lado, no están gustando de cuestiones educativas, ni por cable ni por TV aérea, lo que podría convertirse en un debilitamiento de valores universales en las nuevas generaciones.

\section{Contraste de exposición entre televisión aérea y de paga}

Como se comentó anteriormente, es importante conocer cuál de los dos tipos de televisión están siendo más atractivos para las audiencias que tienen la posibilidad de escoger entre ambos sistemas. Ya que la televisión de paga ofrece un porcentaje mayor de programación extranjera y los estudiantes comentaron gustar de este tipo de materiales en referencia a esta modalidad de TV, es necesario conocer a cuál de los dos modos se exponen más los encuestados para así deducir qué programación es más vista.

El Cuadro 5 muestra que la transmisora más vista por los jóvenes de preparatoria fue el Canal 2 de Televisa ${ }^{3}$. Esto significa que la programación que veian con mayor frecuencia es mexicana, ya que como se ha comentado en repetidas ocasiones, es este el único tipo de información que este canal ofrece. El segundo más visto era D99, que aunque es un canal de cable, ofrece cercanía cultural ya que es de producción local, con conductores hispanoparlantes. Sin embargo, como también se ha mencionado, sus contenidos no son únicamente nacionales o regionales, sino también norteamericanos.

3 Los datos referentes a la frecuencia de exposición a canales de televisión aérea fueron también preguntados en el cuestionario aplicado. Los resultados se encuentran en el reporte completo de la presente investigación. De la Garza, Y. (1996) Patrón de exposición y preferencias programáticas televisivas de los jóvenes de preparatoria de Monterrey y su área conurbada. Tesis de Maestria en Cmunicación, ITESM Campus Monterrey. 
Patrón de exposición televisiva de jóvenes ...

El hecho de que el tercer canal visto con más frecuencia haya sido Tele-Hit vuelve a reforzar la posible "Preferencia Nacional" de estas audiencias ya que, como se ha dicho, este canal ofrece cercanía a través del lenguaje español. El resto de los canales, exceptuando Canal 5 y 7 , son norteamericanos, transmisores de películas y series de esta nacionalidad.

Esto podría significar que, si bien los jóvenes manifestaron una preferencia mayor por productos nacionales, es innegable que también hay una alta exposición hacia materiales extranjeros. Esto es equivalente al grupo de programas que veían: había en general un número mayor de nacionales, pero también se mencionaron dentro de los primeros lugares productos extranjeros.

\section{"Preferencia Nacional" y las variables sexo y clase social}

Como fue mencionado con anterioridad, los estudios cuantitativos relacionados con preferencias han mostrado que las variables sexo y clase social suelen determinar la medida de inclinación de la audiencia hacia contenidos extranjeros. Por lo tanto, un área de interés para el presente estudio era conocer, por un lado, las preferencias de los estudiantes en relación al material importado, pero además era trascendente conocer cómo afecta la clase social ${ }^{4}$ y el sexo para la conformación de estos patrones de exposición.

Se comentó, a grandes rasgos, que el sexo y la clase social son factores de gran importancia ya que algunos estudios han arrojado que las mujeres ven menos televisión y un promedio menor de programación extranjera en contraste con el sexo masculino quien, según estas investigaciones, ve más televisión y se expone en mayor porcentaje a materiales extranjeros. Además, las personas de clase social baja generalmente tienen una preferencia mayor hacia la TV nacional o regional, a diferencia del resto de las personas que manifiestan una mayor preferencia por lo extranjero.

Por esta razón, se decidió analizar las variables sexo y clase social en relación a horas dedicadas a ver televisión, canales aéreos favoritos, programas de televisión aérea favoritos y canales de paga favoritos de los jóvenes de preparatoria en Monterrey.

4 Para determinar la clase social se utilizaron una serie de preguntas dentro de la encuesta aplicada en el presente estudio. La Clase I abarca aquellas personas que mostraron tener un nivel económico y social más alto debido al tipo de casa en el que habitaban, la ocupación de los padres y el número de automóviles que poseían. 


\section{Horas dedicadas a ver televisión por sexo y clase social}

De acuerdo a los resultados de este estudio, se puede aseverar que los estudiantes masculinos de preparatoria de Monterrey entrevistados veían más horas de televisión en comparación con las mujeres. Estas últimas afirmaron ver, en general, 4 horas con una desviación estándar de 2.32, mientras que los chicos veían 4.25 con una desviación estándar de 2.75 .

Cabe mencionar que estos resultados difieren con los de Díaz (1995) quien reportó lo contrario en su investigación con jóvenes de secundaria en Monterrey. El 53.6\% de las mujeres se exponían 5 horas a la televisión mientras que sólo el $35.2 \%$ del sexo masculino lo hacía. Esta discrepancia puede deberse a diversas razones. Una de ellas podría ser la edad, la cual conforme va siendo mayor, diversifica las diversiones y los intereses, lo que hace que las chicas de preparatoria ya no estén tan interesadas en el aparato electrónico como los hombres.

En cuanto al nivel socioeconómico, conforme este aumenta, la exposición a la televisión disminuye. Los muchachos de clase alta veían 3.57 horas; los de clase media 4.23 y los de clase baja 4.45. Esta información si coincidió con la de Díaz (1995) lo que podría significar que los jóvenes en Monterrey pertenecientes al Sector I ven menos TV que los de otros estratos. Esto puede deberse a que los muchachos y muchachas de clases pudientes tienen acceso a muchos tipos de diversiones, a diferencia de sus contrapartes.

\section{Canal favorito por sexo y clase social}

En cuanto a los canales declarados como favoritos por los estudiantes de preparatoria de Monterrey y su área conurbada, los resultados coinciden con aquellos obtenidos en otras investigaciones: las mujeres ven más contenido mexicano, particularmente telenovelas. Los hombres tienen una ligera preferencia por materiales extranjeros.

El primer lugar en preferencia por parte del sexo femenino fue claramente el Canal 2 de Televisa (10 local), el cual ofrece material 100\% mexicano. Los hombres, en contraste, tendieron más a preferir y exponerse a materiales importados a través de los canales 7 de TV-Azteca y XHGC de Televisa. La diferencia entre ambos es que TV-7 ofrece un alto porcentaje de programación procedente de Colombia y Brasil, aunque los programas exitosos del horario estelar son estadounidenses. Mientras tanto, el Canal 6 ofrece series y caricaturas procedentes de los Estados Unidos casi en su totalidad (ver 
Cuadro 6). Esto reitera lo afirmado anteriormente: las mujeres tienen una tendencia mayor a exponerse a materiales nacionales en comparación con los hombres.

En cuanto a la clase social, los resultados arrojados por la investigación hecha con estudiantes de preparatoria de Monterrey y su área conurbada son sorprendentes. Se esperaba encontrar que el canal favorito de las clases media y baja era el de las Estrellas, mientras que la clase alta tendría una preferencia por canales que ofrecieran contenidos extranjeros.

Sin embargo, los estudiantes reportaron gustar por igual del Canal de las Estrellas. De hecho, fue el sector I (alto) quien reportó un mayor porcentaje de favoritismo por esta estación de Televisa, con un $49 \%$, mientras que sólo el $40 \%$ del sector II (medio) y el $38.2 \%$ del sector III (bajo) afirmó lo mismo. El Cuadro 6 ofrece mayor detalle.

Estos resultados son distintos a los obtenidos por Díaz (1995) en Monterrey. La investigadora reportó que, si bien los tres sectores gustaban en primer lugar del Canal 10 , era la clase baja quien lo prefería con una mayor puntuación. El Canal 6 era mayormente preferido por la clase alta.

En conclusión se puede afirmar que los estudiantes prefinieron el canal que ofrece contenidos mexicanos por encima de aquellos que ofrecen tanto nacionales como extranjeros (TV-7) y únicamente materiales importados (XHGC). Estos datos sustentan lo expuesto en relación a la teoría de la "Preferencia Nacional".

\section{Programas de televisión aérea favoritos por sexo y clase social}

Las investigaciones referentes a la "Preferencia Nacional" reportan que, a pesar de que hay una gran oferta de programas extranjeros, la mayoría del material más gustado por las audiencias es nacional o regional. Además, algunos estudios mencionan que son los hombres quienes tienen una mayor preferencia por productos importados (aunque cuantitativamente prefieren más lo nacional), al igual que los miembros de las clases altas. Para corroborar esto, se presenta a continuación el resultado de los cruces entre el programa mencionado como el mł̣s preferido de la televisión aérea contra las variables sexo y clase social.

Después de comparar las preferencias de las mujeres y los hombres en relación al programa de televisión aérea favorito, se pudo comprobar que los muchachos suelen tener una ligera preferencia de lo extranjero por encima de lo nacional. De sus 10 programas predilectos, 5 eran mexicanos y 5 extranjeros, mientras que las muchachas gustaron de 7 programas mexicanos y sólo 4 programas americanos. Sin embargo, es interesante 
resaltar, a la luz de la "Preferencia Nacional", que ninguno de los dos sexos prefirió un mayor número de materiales extranjeros por encima de los mexicanos.

Los programas favoritos fueron las ya tan mencionadas series norteamericanas Los Simpsons y El Principe del Rap, otra vez en los dos primeros lugares, tanto de hombres como de mujeres. Un porcentaje mayor de los chicos veían estas caricaturas norteamericanas (36.5\%) en relación a las muchachas (18.8\%). Lo contrario ocurrió con El Príncipe del Rap en donde fue un número mayor de ellas quienes gustaban de él, 11.4\% contra el $10 \%$ de los hombres. El tercer lugar en ambos fue también el programa de Televisa "Pácatelas", aunque también fueron las chicas las que más gustaron de él (10\%) en relación a los muchachos (4.7\%) (ver Cuadro 7 ).

En cuanto a la clase social y el programa favorito en televisión aérea pudo observarse, en términos generales, que los tres sectores prefirieron en cantidad los materiales nacionales. Sin embargo, conforme descendía el nivel socioeconómico, era mayor el número de programas nacionales incluídos en la lista de más gustados. Esto coincide con los estudios de quienes afirman que a mayor nivel socioeconómico, mayor preferencia por lo extranjero, como afirma Lozano (1994: 234). De los primeros 11 programas gustados por el sector I, 5 eran norteamericanos y 6 mexicanos; de los $14^{5}$ más gustados por el sector II, 6 eran extranjeros y 8 mexicanos y de los 11 más gustados por el sector III, 4 eran importados y 7 nacionales (ver Cuadro 18).

Sin embargo, los tres sectores tuvieron como favoritos, con altísimos porcentajes, los programas Los Simpsons y El Príncipe del Rap. Como ya se ha mencionado anteriormente, sería interesante analizar que valores e ideas transmiten estos programas, qué implicaciones ideológicas podrian tener y cuáles son algunas de las razones por las que son exitosas entre los jóvenes. Particularmente, podría estudiarse qué elementos hicieron que la clase media fuera la que más se identificó con Los Simpsons y la baja con El Príncipe del Rap.

Frecuencia de exposición a canales de televisión de paga por sexo y clase social

Como ya se mencionó, un gran porcentaje de estudiantes tenían contratado en sus casas algún servicio de televisión de paga (61.2\%). A través del instrumento de medición se

5 Se tomó el número 14 debido a que los últimos cuatro programas gustados por el nivel socioeconómico medio tenían el mismo porcentaje. 
Patrón de exposición televisiva de jóvenes ...

preguntó la frecuencia de exposición a canales de ambas empresas. Los resultados presentados a continuación hacen referencia a esta frecuencia, cruzándola con las variables sexo y clase social.

Como puede verse en los Cuadros 9 y 10 no pareció haber diferencia entre hombres y mujeres en cuanto preferencia por lo nacional o extranjero: en lo referente a Cablevisión, de los primeros cinco canales vistos con mayor frecuencia gustaban de 3 canales americanos y 2 mexicanos por igual; en los ofrecidos por Multivisión, gustaban de 4 americanos y sólo uno que, si bien ofrece contenidos americanos y latinoamericanos por igual, es conducido por latinos. ${ }^{6}$ Parece lógico que la mayoría de los canales gustados sean de origen extranjero y que ambos sexos los prefieran por igual ya que, como ya se ha mencionado, una gran parte de la oferta de la televisión de paga se compone de este tipo de canales.

A pesar de que los jóvenes de los tres sectores dijeron gustar básicamente de canales extranjeros (Cuadro 11 y 12), en general se pudo observar que a mayor clase social, mayor exposición a cualquier canal de TV de paga. Las medias de todos los canales de Multivisión y Cablevisión eran casi siempre mayores en el sector I. Esto contrasta con lo analizado en la sección de frecuencia de exposición a canales aéreos y canal aéreo favorito por sexo y clase social, donde se vió que a mayor clase social, menor exposición a canales de televisión aérea. Esto significa que los estratos altos tienen mayor preferencia por la TV de paga y es lógico. Se ha venido diciendo que conforme crecen los recursos económicos, aumenta el interés por materiales extranjeros ya que generalmente es el sector I el que puede tener acceso a diversas fuentes de diversión, viajes, contacto con extranjeros y/o formas televisivas como antena parabólica y TV de paga.

Ya que la mayoría de los canales ofrecidos por las empresas de paga contienen altos promedios de materiales extranjeros y es el sector I el que se está exponiendo en mayor cantidad a ellos, se podría afirmar que a mayor clase social, mayor preferencia por contenidos importados. Estos resultados son coincidentes con los obtenidos por otros investigadores en cuanto a la "Preferencia Nacional".

6 En este caso, cuando se dice canal mexicano se refiere a que es producido en el pais, con conductores nacionales y utilizando el idioma español. Algunos canales de Multivisión son de la misma empresa, pero ofrecen sólo contenidos norteamericanos (como películas) por lo que fueron considerados como extranjeros. 


\section{Conclusiones}

El presente trabajo se fijó cuatro preguntas de investigación en relación a la "Preferencia Nacional", con el fin de aportar nuevos datos a la investigación de comunicación de masas en México. Las preguntas eran ¿cuál es el promedio de exposición a la programación extranjera ofrecida por televisión por parte de los jóvenes de preparatoria en la ciudad de Monterrey? ¿cómo se manifiesta la "Preferencia Nacional" en el grupo investigado? ¿cómo afecta la variable sexo para la exposición y preferencia? ¿cómo afecta la variable clase social para la exposición y preferencia?

Con respecto al patrón de tiempo de exposición al televisor, quedó claro que los entrevistados se exponían un alto promedio de horas a este aparato. De acuerdo a investigaciones como la de Díaz (1995), Lozano (1944), Greenberg y Buselle (1993), entre otros, los niños y muchachos adolescentes están exponiéndose en un promedio muy alto a la televisión. Este medio masivo es, por lo tanto, un elemento importante en sus vidas ya que de él reciben mucha de la información que asimilan del mundo y su alrededor. Esto respalda la necesidad de conocer qué ven estas audiencias ya que la formación de hombres y mujeres del mañana está íntimamente relacionada con los productos que ofrecen las televisoras.

También podríamos afirmar que hay una diferencia entre hombres y mujeres en cuanto al patrón de tiempo de ver televisión. Si bien nuestros hallazgos no son tan claros como para corroborar quién se expone más, si notamos comparando esta investigación con la de Díaz (1995) que en efecto hay una discrepancia. Esto se podría deber al cambio de intereses que implica la transición del nivel medio al nivel medio superior, lo que tal vez significa un cambio en el tiempo de exposición a la televisión conforme al sexo. Es necesario realizar más estudios a este respecto, no únicamente cuantitativos, sino también cualitativos que arrojen luz sobre cuáles podrian ser las consecuencias de una mayor exposición de uno u otro sexo.

Concemiente a la clase social y el patrón de exposición en cuanto a tiempo, son los estratos más bajos los que al parecer pasan un mayor número de horas frente al televisor. Por tanto, podría afirmarse que a mayor nivel socioeconómico, menor exposición a la televisión. La naturaleza descriptiva del presente estudio no contempló el análisis del porqué, pero sería interesante cuestionarse qué hace que la posición socioeconómica marquen una importante diferencia para ver la TV cierto número de horas.

Respecto a la televisión de paga, se debe mencionar que su presencia está creciendo fuertemente en México. Esto es importante ya que parece existir la tendencia de que entre 
Patrón de exposición televisiva de jóvenes ...

más presencia haya de este tipo de TV, mayor preferencia y exposición a materiales norteamericanos por parte de las audiencias. Esto es completamente lógico, ya que estas cadenas comerciales ofrecen casi cien por ciento contenidos extranjeros.

En la ciudad de Monterrey, Cablevisión y Multivisión se han extendido mucho, estando ya en un buen porcentaje de telehogares. Díaz (1995) reportó un número menor de encuestados que tenían contratado este servicio en comparación con los jóvenes de preparatoria que participaron en este estudio. Igualmente, estos muchachos de secundaria tenían una preferencia mayor por programas definidamente mexicanos y después norteamericanos y declararon poco gusto por ambos. En contraste, casi la mayoría de los participantes de esta investigación afirmaron preferir ambos tipos de programas y el porcentaje de menciones para producciones americanas fue mayor que el de mexicanas. Esto podría significar que el gusto por materiales americanos está creciendo conforme aumenta la edad de los jóvenes o el porcentaje de hogares con TV de paga en Monterrey.

Por otro lado, el presente estudio pretendió medir la "Preferencia Nacional" utilizando varios elementos: canal aéreo favorito, programa de TV aérea favorito, frecuencia de ver canales de cable y preferencia explícita de procedencia de programas. Después de realizar la investigación y conocer los resultados, se proponen tres posibles maneras para determinar qué tanto prefieren las audiencias programas nacionales o extranjeros utilizando los anteriores elementos: primero, una sumatoria que permita contrastar el número de programas más vistos y gustados con respecto a su nacionalidad; segundo, analizar la procedencia de los programas declarados como favoritos y tercero, conocer dónde son elaborados los materiales que ofrecen los canales favoritos.

Es indudable que desde la primera perspectiva, la "Preferencia Nacional" quedó constatada en este trabajo. Al igual que lo declarado por otros estudiosos, los resultados de esta investigación arrojan que el promedio de producciones nacionales que los encuestados declararon ver era mayor en relación a aquellos importados. Tal vez no son exactamente compatibles numéricamente y no tan apabullantes como los reportados por Rogers y Antola en Latinoamérica y Lozano en Nuevo Laredo, pero sí claramente identificables.

La segunda perspectiva es la de analizar los programas enlistados como favoritos, pero no sumando y estudiando su procedencia en promedio, sino la nacionalidad de los más exitosos. A diferencia de los resultados obtenidos por otros investigadores, este estudio arrojó que los primeros dos programas con el mayor porcentaje tanto en lo referente a programas aéreos como programas de TV de paga fueron los norteamericanos Los Simpsons y El Principe del Rap. 
Podrían haber varias interpretaciones para este fenómeno. Por un lado, podría significar que el interés por programas nacionales se está debilitando, con las posibles consecuencias culturales que quizás eso acarrearía. Si los programas por los que los jóvenes sienten más atracción son producidos fuera, hacen alusión a un estilo de vida y valores ajenos y sin embargo son seguidos con tal éxito, será porque ante tal diversidad hay igual interés de adaptar esas diferencias en su propia realidad.

Otra posible razón es la edad. Según De la Garde los jóvenes "tienen el consumo más alto de productos estadounidenses, tanto originales (13.2\%) como doblados (10.1\%)" (1993: 42). Aunque este hallazgo se dio en Quebec, podria ser que fuera una característica general de los adolescentes. Ya que la presente investigación se abocó a jóvenes, siendo el promedio de edad 16 años, podría ser que esta particularidad facilite la penetración de programas extranjeros dentro de los grandes favoritos. Habría que investigar si esta situación de encontrar dos o tres materiales importados como los número uno se da entre adultos.

Este mismo investigador ha comentado que un importante aspecto para el éxito de un programa es el doblaje. El considera, de hecho, que un programa traducido puede dejar de ser considerado, en cierto modo, como importado. También se ha dicho que el idioma es de suma importancia, como lo ha destacado Wilkinson (1995), para reducir el descuento cultural y, por lo tanto, facilitar el éxito de una producción. El Príncipe del Rap tiene un doblaje bastante peculiar ya que los comentarios y chistes americanos han sido adaptados a la cultura mexicana, mencionando personajes, situaciones y productos nacionales. Esto podría significar que el gusto por este programa es una muestra de "Preferencia Nacional", por la cercanía en valores, historia, lenguaje y demás situaciones nacionales que la traducción le está agregando.

Pool, otro estudioso de la comunicación de masas, ha dicho que el dominio de los medios norteamericanos se reducirá cuando, poco a poco, los países receptores comiencen a producir programación que pueda ser competencia para lo que se está importando. Por lo pronto, en México no se está desarrollando nada parecido que pudiera desbancar a las dos series mencionadas como más gustadas por los chicos regiomontanos.

El tercer modo de interpretación de la "Preferencia Nacional" podría matizar el análisis anterior. Los canales de televisión aérea y de paga declarados como los vistos con mayor frecuencia fueron el Canal 10 (2 de la Ciudad de México) y D99 de Cablevisión. Esta preferencia de las audiencias por canales que ofrecen contenidos mexicanos, al igual que el promedio de programas más vistos, podrían confirmar que hay 
Patrón de exposición televisiva de jóvenes ...

en los jóvenes de preparatoria entrevistados un mayor gusto por lo nacional que por lo extranjero.

El comportamiento de las audiencias, anteriormente descrito, y la "Preferencia Nacional" parecen estar cercanamente relacionados con las variables sexo y clase social. Las conclusiones en relación a ésto es que son las mujeres las que tienen una mayor preferencia por contenidos nacionales, al igual que las clases bajas. Los hombres y los miembros del sector I parecen preferir un mayor número de programas norteamericanos y exponerse más a canales que ofrecen materiales extranjeros. Aunque, en términos absolutos, prefieren mayormente la programación nacional sobre la extranjera.

Esto podría deberse a cuestiones culturales, tales como el hecho de que las mujeres viven un proceso de socialización tradicionalista, diferente al de los hombres, que las lleva a consumir más productos como las telenovelas (Lozano, 1994). Respecto a la clase social, el sector III tiene una mayor identificación con lo producido nacionalmente porque "refuerza más las identidades tradicionales basadas en lo regional, lo étnico, el dialectoidioma, lo religioso y otros elementos" (Straubhaar, 1993: 92). Además de que las clases altas tienden a tener mayor relación con lo extranjero por su poder adquisitivo que les permite viajar, aprender idiomas, conocer otras culturas y tener relaciones interpersonales con extranjeros.

A través del presente estudio se ha explicado que la "Preferencia Nacional" se refiere a esa posibilidad y habilidad de los televidentes de elegir entre la oferta de programas extranjeros y nacionales y que esta elección es dirigida por sus intereses y su contexto histórico-cultural, inclinándose en orden de preferencia desde lo local, nacional, regional hasta lo extranjero (Wilkinson, 1995; Lozano, 1994; Daz, 1995; De la Garde, 1993; Sepstrup, 1995; Pool, 1977; Straubhaar, 1993; De la Garza, 1996).

Es notorio, sin embargo, que quedan aún muchas interrogantes por contestar. Habrá que analizar en investigaciones posteriores, específicamente, porqué influye el sexo y la clase social en la "Preferencia Nacional"; cómo afecta a la identidad cultural el hecho de que, aún y cuando son pocos, algunos programas norteamericanos se ubican entre los más vistos por las audiencias; cómo determina el conocimiento y dominio del idioma inglés las preferencias y cómo afecta el fuerte crecimiento de la televisión de paga en México y el mundo sobre los gustos de las audiencias.

No será sino a través de más trabajo de investigación y análisis que será posible hallar contestación a estas y otras preguntas que surgen ante la clara y fuerte presencia de materiales extranjeros en la televisión y la actitud de las audiencias denominada como "Preferencia Nacional". 


\section{Cuadro 1}

Programas de televisión aérea favoritos mencionados como No. 1 por los estudiantes de Monterrey

\begin{tabular}{|l|c|c|}
\hline Programa de televisión & Número de casos $^{1}$ & Porcentaje \\
\hline Los Simpsons ${ }^{2}$ & 121 & 27.4 \\
\hline El Príncipe del Rap & 47 & 10.6 \\
\hline Pácatelas & 33 & 7.5 \\
\hline El Calabozo & 13 & 2.9 \\
\hline María la del barrio & 11 & 2.5 \\
\hline Marisol & 11 & 2.5 \\
\hline Futbol & 10 & 2.3 \\
\hline Beverly Hills 90210 & 9 & 2.0 \\
\hline Futbol al día & 9 & 2.0 \\
\hline Expedientes secretos $X$ & 9 & 2.0 \\
\hline Salvados por la campana & 8 & 1.8 \\
\hline Novelas, Canal 10 & 7 & 1.6 \\
\hline Renegado & 7 & 1.6 \\
\hline Tres por tres & 7 & 1.6 \\
\hline Acción & 6 & 1.4 \\
\hline Acapulco, suerpo y alma & 5 & 1.1 \\
\hline Ventaneando & 5 & 1.1 \\
\hline Otros & 124 & 28.1 \\
\hline Total & 442 & 100 \\
\hline
\end{tabular}

1 Este fue el número de nienciones de programas del total de encuestados que confirmaron tener algún tipo de televisión de paga, ya que cada alumno podía hacer referencia a 5 programas diferentes.

2 Los nombres de programas norteamerianos o extranjeros aparecen en cursivas. 
Patrón de exposición televisiva de jóvenes ...

\section{Cuadro 2}

Programas favoritos de televisión de paga de los estudiantes de Monterrey

\begin{tabular}{|l|c|c|}
\hline Programa de televisión & Número de casos $^{1}$ & Porcentaje \\
\hline Los Simpsons & 78 & 8.1 \\
\hline Videos, D99 & 62 & 6.4 \\
\hline Beverly Hills 90210 & 60 & 6.2 \\
\hline Cinema Golden Choice & 51 & 5.3 \\
\hline El Calabozo & 46 & 4.8 \\
\hline Tele Hit & 38 & 4 \\
\hline MTV & 30 & 3.1 \\
\hline Cartoon Network & 27 & 2.8 \\
\hline Expedientes secretos $X$ & 27 & 2.8 \\
\hline Discovery Channel & 26 & 2.7 \\
\hline Modelos & 26 & 2.7 \\
\hline ESPN & 24 & 2.5 \\
\hline Fox & 23 & 2.4 \\
\hline HBo & 22 & 2.3 \\
\hline Melrose Place & 21 & 2.2 \\
\hline Super Estelar Caliente & 18 & 1.9 \\
\hline Basketball & 14 & 1.5 \\
\hline Tele Uno & 14 & 1.5 \\
\hline Cine Canal & 10 & 1.9 \\
\hline Pácatelas & 10 & 1.0 \\
\hline Otros & 335 & 34.4 \\
\hline Total & 962 & 100 \\
\hline
\end{tabular}

1 Este fue el número de menciones de programas del total de encuestados que confirmaron tener algún tipo de televisión de paga, ya que cada alumno podía hacer referencia a 5 programas diferentes.

2 Los nombres de programas norteamericanos o extranjeros aparecen en cursivas. 
Cuadro 3

Frecuencia de exposición de los estudiantes de Monterrey a canales de Cablevisión

\begin{tabular}{|l|c|c|c|}
\hline Canal de Cablevisión & Media* & $\begin{array}{c}\text { Desviación } \\
\text { estándar }\end{array}$ & $\begin{array}{c}\text { Número de } \\
\text { casos }\end{array}$ \\
\hline Canal 99 D99 & 3.88 & 1.18 & 182 \\
\hline Canal 28 Tele Hit (HIT) & 3.60 & 3.34 & 178 \\
\hline Canal 21 FOX & 3.44 & 1.15 & 181 \\
\hline Canal 16 Cinema Golden Ch. (Gold) & 3.31 & 1.11 & 185 \\
\hline Canal 23 Tele UNO (UNO) & 3.08 & 1.33 & 178 \\
\hline Canal 9 Discovery Channel (Disc) & 2.87 & 1.09 & 184 \\
\hline Canal 8 ESPN car & 2.73 & 1.23 & 182 \\
\hline Canal 14 HBo Olé & 2.64 & 1.41 & 177 \\
\hline Canal 18 Cartoon Network (CART) & 2.63 & 1.34 & 182 \\
\hline Canal 15 TNT & 2.51 & 1.04 & 180 \\
\hline Canal 38 Cinemax & 2.49 & 1.38 & 174 \\
\hline Canal 24 CineCanal (CC) & 2.28 & 1.35 & 177 \\
\hline Canal 32 MTV latino & 2.16 & 1.40 & 172 \\
\hline Canal 27 TVC & 2.11 & 1.07 & 177 \\
\hline Canal 19 9 de México & 2.06 & 1.15 & 177 \\
\hline Canal 3 Super Estelar & 2.05 & 1.19 & 185 \\
\hline Canal 5 TV Española (TVE) & 1.88 & 0.88 & 185 \\
\hline Canal 33 Telenovelas & 1.83 & 1.19 & 183 \\
\hline Canal 13 Headlines News & 1.82 & 1.00 & 180 \\
\hline Cable 17 Cable Kin & 1.77 & 0.95 & 181 \\
\hline Canal 98 Pago por evento & 1.69 & 1.10 & 171 \\
\hline Canal 44 Ritmo y son (SON) & 1.68 & 0.99 & 180 \\
\hline Canal 50 Entertainment (E!) & 1.61 & 1.05 & 172 \\
\hline Canal 43 CBs & 1.79 & 1.03 & 171 \\
\hline Canal 54 Cine mexicano por cable & 1.59 & 0.98 & 170 \\
(CMC) & 1.54 & 1.01 & 174 \\
\hline Canal 37 Televisión Internacional (TVI) & & & \\
\hline Canal 42 ABC & & 1.15 & 177 \\
\hline
\end{tabular}


Patrón de exposición televisiva de jóvenes ...

Cuadro 3

(continuación)

\begin{tabular}{|l|c|c|c|}
\hline Canal de Clabelvisión & Media* & $\begin{array}{c}\text { Desviación } \\
\text { estándar }\end{array}$ & Número de casos \\
\hline Canal 49 Art & 1.47 & 1.10 & 171 \\
\hline Canal 55 CNN & 1.45 & 0.88 & 166 \\
\hline Canal 29 Teatro Alemada (TALA) & 1.44 & 0.78 & 177 \\
\hline Canal 46 Travel Channel & 1.37 & 0.83 & 173 \\
\hline Canal 45 Gems & 1.36 & 0.75 & 173 \\
\hline Canal 47 Prime Network & 1.36 & 0.77 & 173 \\
\hline Canal 20 Internet & 1.30 & 0.68 & 169 \\
\hline Canal 39 40 de México & 1.28 & 0.63 & 174 \\
\hline Canal 51 Weather Channel & 1.28 & 0.60 & 171 \\
\hline Canal 31 Deustche Welle & 1.27 & 0.60 & $171^{\prime}$ \\
\hline Canal 41 IPN 11 de México & 1.25 & 0.57 & 174 \\
\hline Canal 52 Sur & 1.24 & 0.58 & 174 \\
\hline Canal 53 Mind Extension & 1.24 & 0.90 & 168 \\
\hline University & & & 172 \\
\hline Canal 48 Worldnet & 1.18 & 0.53 & . \\
\hline
\end{tabular}

* Media en escala: 1 "Nunca", 2 "Rara vez", 3 "De vez en cuando", 4 "Con frecuencia", 5 "Sicmpre". 


\section{Cuadro 4}

Frecuencia de exposición de los estudiantes de Monterrey a canales de Multivisión

\begin{tabular}{|l|c|c|c|}
\hline Canal de Multivisión & Media* & $\begin{array}{c}\text { Desviación } \\
\text { estándar }\end{array}$ & Número de casos \\
\hline Canal 15 FoX & 3.58 & 1.22 & 58 \\
\hline Canal 18 Multicinema * & 3.35 & 1.14 & 60 \\
\hline Canal 16 ESPN & 3.32 & 1.34 & 56 \\
\hline Canal 12 MTV Latino & 3.25 & 1.42 & 56 \\
\hline Canal 1 Tele UNo & 3.11 & 1.10 & 60 \\
\hline Canal 8 USA & 3.09 & 1.06 & 54 \\
\hline Canal 27 Cinemax & 2.88 & 1.49 & 52 \\
\hline Canal 26 HBO & 2.85 & 1.54 & 54 \\
\hline Canal 6 ZAZ & 2.68 & 1.11 & 58 \\
\hline Canal 14 Cinecanal & 2.67 & 1.49 & 56 \\
\hline Canal 3 AS & 2.58 & 1.09 & 58 \\
\hline Canal 10 TNT & 2.51 & 1.09 & 58 \\
\hline Canal 24 Cartoon Network & 2.50 & 1.35 & 58 \\
\hline Canal 28 Mvs & 2.47 & 1.35 & 53 \\
\hline Canal 17 Discovery Channel & 2.26 & 1.40 & 52 \\
\hline Canal 23 Multi Premier & 2.07 & 1.28 & 53 \\
\hline Canal 23 Pay Per View 3 & 2.05 & 1.18 & 54 \\
\hline Canal 31 Pay Per View 1 & 1.94 & 1.03 & 54 \\
\hline Canal 32 Pay Per View 2 & 1.94 & 1.01 & 54 \\
\hline Canal 19 NBC Noticias & 1.90 & 1.07 & 55 \\
\hline Canal 34 Pay Per View 4 & 1.90 & 1.07 & 53 \\
\hline Canal 21 Net Pack & 1.81 & 1.25 & 53 \\
\hline Canal 20 CNN & 1.58 & 0.90 & 53 \\
\hline Canal 25 Cine Latino & 1.51 & 0.99 & 52 \\
\hline \hline
\end{tabular}

* Media en escala: 1 "Nunca", 2 "Rara vez", 3 "De vez en cuando", 4 "Con frecuencia", 5 "Siempre". 
Patrón de exposición televisiva de jóvenes ...

\section{Cuadro 5}

Comparación de frecuencia de exposición a canales de televisión aérea y de paga

\begin{tabular}{|l|c|c|c|}
\hline Canal & Media* $^{*}$ & $\begin{array}{c}\text { Desviación } \\
\text { estándar }\end{array}$ & Número de casos \\
\hline Canal 2 de Televisa & 4.07 & 1.37 & 427 \\
\hline Canal 99 D99 & 3.88 & 1.18 & 182 \\
\hline Canal 28 Tele Hit (HIT) & 3.60 & 3.34 & 178 \\
\hline Canal 15,21 FoX & 3.51 & 1.18 & 239 \\
\hline Canal 18 Multicinema & 3.35 & 1.14 & 60 \\
\hline Canal 6 XHGC & 3.34 & 1.06 & 434 \\
\hline Canal 16 ESPN & 3.32 & 1.34 & 56 \\
\hline Canal 16 Cinema Golden Choice & 3.31 & 1.11 & 185 \\
\hline Canal 12 MTV Latino & 3.25 & 1.42 & 56 \\
\hline Canal 7 TV 7 & 3.22 & 1.29 & 425 \\
\hline Canal 1 Tele UNO & 3.11 & 1.10 & 60 \\
\hline Canal 8 USA & 3.09 & 1.06 & 54 \\
\hline Canal 23 Tele UNO (UNO) & 3.08 & 1.33 & 178 \\
\hline
\end{tabular}

" Media en escala: 1 "Nunca", 2 "Rara vez", 3 "De vez en cuando", 4 "Con frecuencia", 5 "Siempre". 


\section{Cuadro 6}

Canales favoritos de televisión aérea de Monterrey por sexo y clase social

\begin{tabular}{|l|c|c|c|c|c|}
\hline Canal & Mujeres & Hombres & Clase I & Clase II & Clase III \\
\cline { 2 - 7 } & $\%$ & $\%$ & $\%$ & $\%$ & $\%$ \\
\hline Canal 10 & 67.3 & 13.7 & 49 & 40 & 38.2 \\
\hline Canal 7 TV7 & 15.7 & 39.3 & 18.8 & 32.7 & 23.6 \\
\hline Canal 6 XHGC Canal15 & 10.5 & 25.1 & 13.5 & 16.8 & 21.1 \\
\hline Canal 4 13TV Azteca & 2.2 & 7.1 & 7.3 & 3.2 & 4.9 \\
\hline Canal 2 & 0.4 & 0.5 & 1.0 & 0 & 0.8 \\
\hline Canal 12 & 0 & 2.4 & 0 & 0.9 & 2.4 \\
\hline Canal 22 & 0.9 & 2.8 & 0 & 0.5 & 5.7 \\
\hline Canal 34 & 0.9 & 0.5 & 0 & 0.9 & 0.8 \\
\hline Canal 28 & 0 & 0.5 & 0 & 0.5 & 0 \\
\hline Total & 100 & 100 & 100 & 100 & 100 \\
\hline \hline
\end{tabular}


Patrón de exposición televisiva de jóvenes ...

\section{Cuadro 7}

Programas favoritos de televisión aérea de Monterrey por sexo

\begin{tabular}{|l|c|c|c|c|}
\hline \multirow{2}{*}{ Programa } & \multicolumn{2}{|c|}{ Mujeres } & \multicolumn{2}{c|}{ Hombres } \\
\cline { 2 - 5 } & $\begin{array}{c}\text { Número de } \\
\text { menciones }\end{array}$ & $\%$ & $\begin{array}{c}\text { Número de } \\
\text { menciones }\end{array}$ & $\%$ \\
\hline Los Simpsons & 43 & 18.8 & 77 & 36.5 \\
\hline El Principe del Rap & 26 & 11.4 & 21 & 10 \\
\hline Pácatelas & 23 & 10.0 & 10 & 4.7 \\
\hline María la del barrio & 11 & 4.8 & 0 & 0 \\
\hline Marisol & 11 & 4.8 & 0 & 0 \\
\hline Beverly Hills 90210 & 8 & 3.5 & 1 & 0.5 \\
\hline Novelas del Canal 10 & 7 & 3.1 & 0 & 0 \\
\hline El Calabozo & 6 & 2.6 & 7 & 3.3 \\
\hline Tres por tres & 6 & 2.6 & 1 & 0.5 \\
\hline Acapulco, cuerpo y alma & 5 & 2.2 & 0 & 0 \\
\hline Ventaneando & 5 & 2.2 & 0 & 0 \\
\hline Salvados por la campana & 4 & 1.8 & 4 & 1.9 \\
\hline Azul & 3 & 1.3 & 0 & 0 \\
\hline Desvelados & 3 & 1.3 & 0 & 0 \\
\hline Morelia & 3 & 1.3 & 0 & 0 \\
\hline Sábado Gigante & 3 & 1.3 & 0 & 0 \\
\hline Expedientes secretos $X$ & 3 & 1.3 & 6 & 2.8 \\
\hline Renegado & 2 & 0.9 & 5 & 2.4 \\
\hline Acción & 0 & 0 & 6 & 2.8 \\
\hline Caballeros del zodiaco & 0 & 0 & 3 & 1.4 \\
\hline Futbol & 0 & 0 & 10 & 4.7 \\
\hline Futbol al día & 57 & 24.9 & 51 & 24.2 \\
\hline Otros & 100 & 211 & 100 \\
\hline Total & 3 & 0 & 9 & 4.3 \\
\hline & 3 & & 0 & 0 \\
\hline
\end{tabular}

1 Este fue el número de programas mencionados como número 1. Los estudiantes podian responder cinco programas diferentes por orden de importancia.

2 Los nombres de programas norteamericanos o extranjeros aparecen en cursivas. 


\section{Cuadro 8}

Programas favoritos de televisión aérea de Monterrey por clase social

\begin{tabular}{|l|c|c|c|c|c|c|}
\hline \multirow{2}{*}{ Canal } & \multicolumn{2}{|c|}{ Clase I } & \multicolumn{2}{c|}{ Clase II } & \multicolumn{2}{c|}{ Clase III } \\
\cline { 2 - 7 } & $\begin{array}{c}\text { Número } \\
\text { de casos }\end{array}$ & $\%$ & $\begin{array}{c}\text { Número } \\
\text { de casos }\end{array}$ & $\%$ & $\begin{array}{c}\text { Número } \\
\text { de casos }\end{array}$ & $\%$ \\
\hline Los Simpsons ${ }^{2}$ & 25 & 26.0 & 68 & 30.9 & 28 & 22.8 \\
\hline El Príncipe del Rap & 7 & 7.3 & 19 & 8.6 & 21 & 17.1 \\
\hline Beverly Hills 90210 & 4 & 4.2 & 4 & 1.8 & 1 & 0.8 \\
\hline El Calabozo & 4 & 4.2 & 6 & 2.7 & 3 & 2.4 \\
\hline Pácatelas & 4 & 4.2 & 15 & 6.8 & 14 & 11.4 \\
\hline María la del barrio & 3 & 3 & 3 & 1.4 & 5 & 4.1 \\
\hline Acción & 2 & 2.1 & 2 & 0.9 & 1 & 0.8 \\
\hline Caballeros del zodiaco & 2 & 2.1 & 1 & 0.5 & 0 & 0 \\
\hline Marisol & 2 & 2.1 & 4 & 1.8 & 5 & 4.1 \\
\hline Tres por tres & 2 & 2.1 & 5 & 2.3 & 0 & 0 \\
\hline Ventaneando & 2 & 2.1 & 3 & 1.4 & 0 & 0 \\
\hline Acapulco, cuerpo y & 1 & 1.0 & 3 & 1.4 & 1 & 0.8 \\
\hline alma & 1 & & & & & \\
\hline Azul & 1 & 1.0 & 2 & 0.9 & 0 & 0 \\
\hline Futbol & 1 & 1.0 & 3 & 1.4 & 6 & 4.9 \\
\hline Futbol al día & 1 & 1.0 & 2 & 0.9 & 6 & 4.9 \\
\hline Morelia & 1 & 1.0 & 0 & 0 & 2 & 1.6 \\
\hline Novelas del canal 10 & 1 & 1.0 & 5 & 2.3 & 0 & 0 \\
\hline Renegado & 1 & 1.0 & 2 & 0.9 & 4 & 3.3 \\
\hline MTV & 0 & 0 & 3 & 1.4 & 0 & 0 \\
\hline Expedientes secretos X & 0 & 0 & 7 & 3.2 & 2 & 1.6 \\
\hline Otros & 64 & 66.6 & 157 & 71.4 & 99 & 80.5 \\
\hline Total & 32 & 100 & 63 & 100 & 24 & 100 \\
\hline
\end{tabular}

1 Este fue el número de programas mencionados como número 1 . Los estudiantes podían responder cinco programas diferentes por orden de importancia.

2 Los nombres de programas norteamericanos o extranjeros aparecen en cursivas. 


\section{Cuadro 9}

Frecuencia de exposición de los estudiantes de Monterrey a canales de Cablevisión por sexo

\begin{tabular}{|c|c|c|c|c|}
\hline \multirow[t]{2}{*}{ Canal de Cablevisión } & \multicolumn{2}{|c|}{ Mujeres } & \multicolumn{2}{|c|}{ Hombres } \\
\hline & Media* & $\begin{array}{c}\text { Desviación } \\
\text { estándar }\end{array}$ & Media & \begin{tabular}{|c|c|}
$\begin{array}{c}\text { Desviación } \\
\text { estándar }\end{array}$ \\
\end{tabular} \\
\hline Canal 15 TNT & 3.11 & 1.47 & 1.92 & 1.32 \\
\hline Canal 99 D99 1 & 2.76 & 2.15 & 2.42 & 1.93 \\
\hline Canal 28 Tele Hit (HIT) & 2.55 & 2.04 & 2.33 & 3.38 \\
\hline $\begin{array}{l}\text { Canal } 16 \text { Cinema Golden } \mathrm{Ch} . \\
\text { (Gold) }\end{array}$ & 2.48 & 1.85 & 2.29 & 1.72 \\
\hline Canal 23 Tele Uno (UNO) & 2.44 & 1.86 & 2.03 & 1.57 \\
\hline Canal 21 FOX & 2.38 & 1.77 & 2.44 & 1.93 \\
\hline $\begin{array}{l}\text { Canal } 18 \text { Cartoon Network } \\
\text { (CART) }\end{array}$ & 2.25 & 1.71 & 1.90 & 1.35 \\
\hline Canal 14 HBo Olé & 2.17 & 1.65 & 1.93 & $\therefore 1.48$ \\
\hline $\begin{array}{l}\text { Canal 9 Discovery Channel } \\
\text { (Disc) }\end{array}$ & $2: 10$ & 1.42 & 2.29 & 1.73 \\
\hline Canal 24 CineCanal (CC) & 2 & 1.50 & 1.82 & 1.29 \\
\hline Canal 38 Cine Max & 1.97 & 1.48 & 1.98 & 1.51 \\
\hline Canal 3 Super Estelar & 1.95 & 1.38 & 1.75 & 1.13 \\
\hline Canal 33 Telenovelas & 1.94 & 1.39 & 1.55 & it 0.85 \\
\hline Canal 8 ESPN & 1.87 & 1.26 & 2.38 & 1.79 \\
\hline Canal 27 Tve & 1.84 & 1.21 & 1.84 & 1.26 \\
\hline Canal 199 de México & 1.83 & 1.27 & 1.82 & 1.22 \\
\hline Canal 32 MTV Latino & 1.81 & 1.31 & 1.86 & 1.42 \\
\hline Canal 17 Cable Kin & 1.81 & 1.14 & 1.63 & 0.96 \\
\hline Canal 5 TV Española (TVE) & 1.79 & 1.09 & 1.77 & 1.10 \\
\hline Canal 44 Ritmo y Son (SON) & 1.72 & 1.06 & 1.64 & 1.01 \\
\hline Canal 98 Pago por Evento & 1.7 & 1.14 & 1.60 & 0.99 \\
\hline Canal 13 Headlines News & 1.67 & 0.98 & 1.81 & 1.21 \\
\hline Canal 43 cBS & 1.67 & 0.99 & 1.62 & 1.03 \\
\hline
\end{tabular}


Cuadro 9

(continuación)

\begin{tabular}{|c|c|c|c|c|}
\hline \multirow[t]{2}{*}{ Canal de Cablevisión } & \multicolumn{2}{|c|}{ Mujeres } & \multicolumn{2}{|c|}{ Hombres } \\
\hline & Media* & \begin{tabular}{|c|} 
Desviación \\
estámdar \\
\end{tabular} & Media & $\begin{array}{c}\text { Desviación } \\
\text { estándar }\end{array}$ \\
\hline Canal 50 Entertainment (E!) & 1.65 & 1.06 & 1.59 & 0.98 \\
\hline $\begin{array}{l}\text { Canal } 37 \text { Televisión Internacional } \\
\text { (TVI) }\end{array}$ & 1.65 & 0.99 & 1.60 & 1.13 \\
\hline Canal 54 Cine Mexicano por Cable & 1.63 & 1.04 & 1.58 & 0.92 \\
\hline Canal 49 Art & 1.62 & 1.12 & 1.51 & 0.83 \\
\hline Canal 29 Teatro Alameda (TALA) & 1.62 & 0.89 & 1.53 & 0.83 \\
\hline Canal $42 \mathrm{ABC}$ & 1.59 & 0.94 & 1.61 & 1.03 \\
\hline Canal $55 \mathrm{CNN}$ & 1.57 & 0.91 & 1.52 & 0.86 \\
\hline Canal 45 Gems & 1.57 & 0.86 & 1.48 & 0.75 \\
\hline Canal 46 Travel Channel & 1.55 & 0.83 & 1.52 & 0.86 \\
\hline Canal 47 Prime Network & 1.53 & 0.80 & 1.53 & 0.85 \\
\hline Canal 20 Internet & 1.53 & 0.83 & 1.45 & 0.67 \\
\hline Canal 3940 de México & 1.51 & 0.75 & 1.49 & 0.73 \\
\hline Canal 51 Weather Channel & 1.51 & 0.73 & 1.48 & 0.73 \\
\hline Canal 41 IPN 11 de México & 1.50 & 0.73 & 1.48 & 0.69 \\
\hline Canal 52.Sur. & 1.49 & 0.71 & 1.47 & 0.70 \\
\hline Canal 31 Deustche Welle & 1.48 & 0.68 & 1.49 & 0.77 \\
\hline Canal 53 Mind Extension University & 1.48 & 0.71 & 1.46 & 0.93 \\
\hline Canal 48 Worldnet & 1.47 & 0.65 & 1.45 & 0.67 \\
\hline
\end{tabular}

* Media en escala: 1 "Nunca", 2 "Rara vez", 3 "De vez en cuando", 4 "Con frecuencia", 5 "Siempre". 
Cuadro 10 .

Frecuencia de exposición de los estudiantes de Monterrey a canales de Multivisión por sexo

\begin{tabular}{|l|c|c|c|c||}
\hline \multicolumn{1}{|c|}{ Canal de Multivisión } & \multicolumn{2}{c|}{ Mujeres } & \multicolumn{2}{c|}{ Hombres } \\
\cline { 2 - 5 } & Media* & $\begin{array}{c}\text { Desviación } \\
\text { estándar }\end{array}$ & Media & $\begin{array}{c}\text { Desviación } \\
\text { estándar }\end{array}$ \\
\hline Canal 1 Tele UNo & 1.41 & 1.19 & 1.43 & 1.09 \\
\hline Canal 18 Multicinema & 1.39 & 1.16 & 1.52 & 1.28 \\
\hline Canal 15 Fox & 1.38 & 1.18 & 1.56 & 1.39 \\
\hline Canal 6 ZAZ & 1.33 & 1.03 & 1.37 & 0.95 \\
\hline Canal 12 MTV Latino & .31 & 1.01 & 1.55 & 1.39 \\
\hline Canal 24 Cartoon Network & 1.31 & 1.01 & 1.34 & 0.94 \\
\hline Canal 8 USA & 1.30 & 0.96 & 1.46 & 1.18 \\
\hline Canal 26 HBo & 1.28 & 0.93 & 1.42 & 1.21 \\
\hline Canal 14 Cine Canal & 1.27 & 0.92 & 1.41 & 1.14 \\
\hline Canal 3 AS & 1.27 & 0.88 & 1.41 & 1.03 \\
\hline Canal 27 Cine Max & 1.26 & 0.89 & 1.42 & 1.21 \\
\hline Canal 10 TNT & 1.26 & 0.85 & 1.40 & 1.02 \\
\hline Canal 16 ESPN & 1.24 & 0.82 & 1.61 & 1.49 \\
\hline Canal 28 MVs & 1.24 & 0.84 & 1.35 & 1.01 \\
\hline Canal 17 Discovery Channel & 1.21 & 0.78 & 1.32 & 0.96 \\
\hline Canal 23 Multi Premier & 1.21 & 0.75 & 1.29 & 0.86 \\
\hline Canal 33 Pay Per View 3 & 1.21 & 0.75 & 1.29 & 0.83 \\
\hline Canal 31 Pay Per View 1 & 1.21 & 0.75 & 1.26 & 0.71 \\
\hline Canal 32 Pay Per View 2 & 1.21 & 0.75 & 1.26 & 0.70 \\
\hline Canal 34 Pay Per View 4 & 1.20 & 0.74 & 1.25 & 0.69 \\
\hline Canal 19 NBC Noticias & 1.16 & 0.56 & 1.32 & 0.87 \\
\hline Canal 25 Cine Latino & 1.15 & 0.53 & 1.20 & 0.65 \\
\hline Canal 21 Net Pack & 1.14 & 0.53 & 1.29 & 0.89 \\
\hline Canal 20 CNN & 1.13 & 0.46 & 1.25 & 0.72 \\
\hline
\end{tabular}

* Media en escala: 1 "Nunca", 2 "Rara vez", 3 "De vez en cuando", 4 "Con frecuencia", 5 "Siempre". 


\section{Cuadro 11}

Frecuencia de exposición de los estudiantes de Monterrey a canales de Cablevisión por clase social

\begin{tabular}{|l|c|c|c|c|c|c|}
\hline Canal de Cablevisión & \multicolumn{2}{|c|}{ Clase I } & \multicolumn{2}{c|}{ Clase II } & \multicolumn{2}{c|}{ Clase III } \\
\cline { 2 - 7 } & Media* & $\begin{array}{c}\text { Desviación } \\
\text { estándar }\end{array}$ & Media & $\begin{array}{c}\text { Desviación } \\
\text { estándar }\end{array}$ & Media & $\begin{array}{c}\text { Desviación } \\
\text { estándar }\end{array}$ \\
\hline Canal 99 D99 & 3.19 & 2.07 & 2.81 & 2.10 & 1.74 & 1.68 \\
\hline Canal 28 Tele Hit (HIT) & 2.93 & 1.96 & 2.74 & 3.46 & 1.54 & 1.34 \\
\hline Canal 21 Fox & 2.88 & 1.79 & 2.69 & 1.96 & 1.52 & 1.33 \\
\hline Canal 16 Cinema & 2.82 & 1.76 & 2.66 & 1.89 & 1.54 & 1.27 \\
\hline Golden Ch. & & & & & & \\
\hline Canal 14 HBo Olé & 2.79 & 1.81 & 2.12 & 1.59 & 1.35 & 0.93 \\
\hline Canal 23 Tele UNo & 2.74 & 1.87 & 2.42 & 1.78 & 1.52 & 1.28 \\
(UNo) & & & & & & \\
\hline Canal 18 Cartoon & 2.59 & 1.73 & 2.15 & 1.50 & 1.56 & 1.36 \\
Network & & & & & & \\
\hline Canal 38 Cine Max & 2.59 & 1.69 & 1.99 & 1.48 & 1.45 & 1.12 \\
\hline Canal 9 Discovery & 2.58 & 1.60 & 2.39 & 1.64 & 1.52 & 1.22 \\
Channel & & & & & & \\
\hline Canal 8 EspN & 2.55 & 1.60 & 2.32 & 1.64 & 1.41 & 1.06 \\
\hline Canal 15 TNT & 2.35 & 1.50 & 2.23 & 1.47 & 1.39 & 0.95 \\
\hline Canal 24 Cine Canal & 2.34 & 1.58 & 1.94 & 1.35 & 1.50 & 1.22 \\
\hline Canal 32 MTV Latino & 2.29 & 1.56 & 1.90 & 1.37 & 1.35 & 1 \\
\hline Canal 13 & 2.17 & 1.31 & 1.80 & 1.10 & 1.26 & 0.65 \\
HeadlinesNews & & & & & & \\
\hline Canal 50 Entertainment & 2.09 & 1.31 & 1.62 & 0.94 & 1.26 & 0.73 \\
\hline Canal 27 TvC & 2.08 & 1.17 & 2 & 1.32 & 1.37 & 0.97 \\
\hline Canal 33 Telenovelas & 2.06 & 1.26 & 1.83 & 1.19 & 1.36 & 0.95 \\
\hline Canal 19 9 de México & 2.03 & 1.19 & 1.99 & 1.34 & 1.35 & 0.96 \\
\hline Canal 3 Super Estelar & 2.02 & 1.14 & 1.99 & 1.33 & 1.49 & 1.20 \\
\hline Canal 5 Tv Española & 2.01 & 1.05 & 1.94 & 1.16 & 1.32 & 0.82 \\
\hline Canal 17 Cable Kin & 2 & 1.10 & 1.75 & 0.98 & 1.41 & 1.04 \\
\hline
\end{tabular}


Patrón de exposición televisiva de jóvenes ...

Cuadro 11

(continuación)

\begin{tabular}{|l|c|c|c|c|c|c|}
\hline \multirow{2}{*}{ Canal de Cablevisión } & \multicolumn{2}{|c|}{ Clase I } & \multicolumn{2}{c|}{ Clase II } & \multicolumn{2}{c|}{ Clase III } \\
\cline { 2 - 7 } & Media* & $\begin{array}{c}\text { Desviación } \\
\text { estándar }\end{array}$ & Media & $\begin{array}{c}\text { Desviación } \\
\text { estándar }\end{array}$ & $\begin{array}{c}\text { Media } \\
\text { estándar }\end{array}$ \\
\hline Canal 43 CBS & 1.99 & 1.22 & 1.64 & 0.98 & 1.26 & 0.69 \\
\hline Canal 42 ABC & 1.99 & 1.20 & 1.63 & 0.97 & 1.24 & 0.65 \\
\hline $\begin{array}{l}\text { Canal 37 Televisión } \\
\text { Internacional }\end{array}$ & 1.97 & 1.45 & 1.65 & 0.92 & 1.29 & 0.77 \\
\hline Canal 98 Pago por Eve & 1.94 & 1.24 & 1.72 & 1.07 & 1.28 & 0.77 \\
\hline Canal 44 Ritmo y Son & 1.87 & 0.95 & 1.77 & 1.09 & 1.36 & 0.94 \\
\hline Canal 47 Prime Network & 1.87 & 1.01 & 1.55 & 0.79 & 1.20 & 0.51 \\
\hline Canal 55 CNN & 1.86 & 1.05 & 1.58 & 0.89 & 1.20 & 0.51 \\
\hline $\begin{array}{l}\text { Canal 54 Cine Mex por } \\
\text { Cable }\end{array}$ & 1.84 & 1 & 1.67 & 0.98 & 1.29 & 0.85 \\
\hline Canal 49 Art & 1.82 & 0.96 & 1.63 & 1.12 & 1.22 & 0.57 \\
\hline $\begin{array}{l}\text { Canal 46 Travel } \\
\text { Channel. }\end{array}$ & 1.80 & 0.95 & 1.55 & 0.75 & 1.28 & 0.80 \\
\hline Canal 45 Gems & 1.80 & 0.92 & 1.57 & 0.80 & 1.22 & 0.62 \\
\hline Canal 20 Internet & 1.77 & 0.88 & 1.53 & 0.75 & 1.21 & 0.51 \\
\hline Canal 51 Weather Ch. & 1.76 & 0.83 & 1.54 & 0.74 & 1.19 & 0.47 \\
\hline $\begin{array}{l}\text { Canal 29 Teatro } \\
\text { Alemada }\end{array}$ & 1.75 & 0.82 & 1.64 & 0.89 & 1.30 & 0.77 \\
\hline Canal 39 40 de México & 1.71 & 0.76 & 1.56 & 0.77 & 1.21 & 0.56 \\
\hline Canal 48 Worldnet & 1.69 & 0.78 & 1.48 & 0.60 & 1.20 & 0.49 \\
\hline $\begin{array}{l}\text { Canal 31 Deustcher } \\
\text { Welle }\end{array}$ & 1.68 & 0.70 & 1.55 & 0.77 & 1.22 & 0.56 \\
\hline $\begin{array}{l}\text { Canal 41 IPN 11 de } \\
\text { México }\end{array}$ & 1.68 & 0.67 & 1.56 & 0.78 & 1.20 & 0.47 \\
\hline $\begin{array}{l}\text { Canal 53 Mind } \\
\text { Extensión U. }\end{array}$ & 1.67 & 0.73 & 1.53 & 0.96 & 1.18 & 0.45 \\
\hline Canal 52 Sur & 1.65 & 0.63 & 1.56 & 0.79 & 1.20 & 0.49 \\
\hline
\end{tabular}

* Media en escala: 1 "Nunca", 2 "Rara vez", 3 "De vez en cuando", 4 "Con frecuencia", 5 "Siempre". 


\section{Cuadro 12}

Frecuencia de exposición de los estudiantes de Monterrey a canales de Multivisión por clase social

\begin{tabular}{|l|c|c|c|c|c|c|}
\hline \multicolumn{1}{|c|}{ Canal de Multivisión } & \multicolumn{2}{|c|}{ Clase I } & \multicolumn{2}{c|}{ Clase II } & \multicolumn{2}{c|}{ Clase III } \\
\cline { 2 - 7 } & Media* & $\begin{array}{c}\text { Desviación } \\
\text { estándar }\end{array}$ & & $\begin{array}{c}\text { Mediación } \\
\text { estándar }\end{array}$ & Media & $\begin{array}{c}\text { Desviación } \\
\text { estándar }\end{array}$ \\
\hline Canal 15 FOX & 1.56 & 1.39 & 1.52 & 1.35 & 1.30 & 1.07 \\
\hline Canal 16 EsPN & 1.55 & 1.41 & 1.45 & 1.24 & 1126 & 0.93 \\
\hline Canal 26 HBO & 1.54 & 1.32 & 1.38 & 1.14 & 1.13 & 0.61 \\
\hline Canal 14 Cinecanal & 1.51 & 1.29 & 1.38 & 1.09 & 1.13 & 0.59 \\
\hline Canal 12 MTV Latino & 1.49 & 1.25 & 1.43 & 1.18 & 1.37 & 1.25 \\
\hline Canal 18 Multicinema & 1.46 & 1.16 & 1.52 & 1.33 & 1.32 & 1.05 \\
\hline Canal 1 Tele UNo & 1.45 & 1.18 & 1.49 & 1.23 & 1.27 & 0.91 \\
\hline Canal 27 Cinemax & 1.45 & 1.22 & 1.40 & 1.16 & 1.14 & 0.64 \\
\hline Canal 8 USA & 1.39 & 1.05 & 1.41 & 1.12 & 1.30 & 1.04 \\
\hline Canal 10 TNT & 1.36 & 0.98 & 1.37 & 0.98 & 1.23 & 0.82 \\
\hline Canal 6 ZAZ & 1.35 & 0.94 & 1.40 & 1.06 & 1.26 & 0.90 \\
\hline Canal 24 Cartoon & 1.35 & 0.98 & 1.38 & 1.07 & 1.21 & 0.76 \\
\hline Network & & & & & & \\
\hline Canal 17 Discovery & 1.34 & 0.90 & 1.33 & 1.04 & 1.08 & 0.36 \\
\hline Channel & & & 1.3 & & & \\
\hline Canal 3 AS & 1.31 & 0.79 & 1.40 & 1.07 & 1.25 & 0.84 \\
\hline Canal 33 Pay per view 3 & 1.30 & 0.91 & 1.27 & 0.78 & 1.17 & 0.69 \\
\hline Canal 21 Net Pack & 1.30 & 0.84 & 1.26 & 0.84 & 1.07 & 0.26 \\
\hline Canal 23 Multi Premir & 1.29 & 0.83 & 1.32 & 0.96 & 1.08 & 0.30 \\
\hline Canal 28 Mvs & 1.28 & 0.81 & 1.31 & 0.93 & 1.27 & 1.01 \\
\hline Canal 31 Pay per view 1 & 1.28 & 0.81 & 1.25 & 0.71 & 1.18 & 0.70 \\
\hline Canal 19 NBC Noticias & 1.28 & 0.80 & 1.25 & 0.78 & 1.18 & 0.64 \\
\hline Canal 32 Pay per view 2 & 1.27 & 0.80 & 1.25 & 0,71 & 1.18 & 0.70 \\
\hline Canal 20 cNN & 1.27 & 0.78 & 1.21 & 0.63 & 1.08 & 0.30 \\
\hline Canal 34 Pay per view 4 & 1.26 & 0.78 & 1.24 & 0.71 & 1.17 & 0.69 \\
\hline Canal 25 Cine Latino & 1.25 & 0.72 & 1.20 & 0.65 & 1.08 & 0.30 \\
\hline
\end{tabular}

* Media en escala: 1 "Nunca", 2 "Rara vez", 3 "De vez en cuando", 4 "Con frecuencia", 5 "Siempre". 
Patrón de exposición televisiva de jóvenes ...

\section{Referencias Bibliográficas}

ACEVEs, F. (1991) "La televisión y los tapatíos. Un atisbo al entreveramiento horario de transmisión, menú programático y patrones de exposición". Comunicación y Sociedad, núm. 13, septiembre-diciembre, pp. 131-161.

BILTEREYST, D. "Qualitative Audience Research and Transnational Media Effects". European Journal of Communication, vol. 10 (2), pp. 245-270.

DE LA GARDE, R. (1993) "Dare we compare?" en De la Garde, R., Gilsdorf W. y Wechselmann, I. Small Nations, Big Neighbour, John Libbey and Company, UK.

DE LA GARZA, Y. "Patrón de exposición y preferencias programáticas televisivas de los jóvenes de preparatoria de Monterrey y su área conurbada". Tesis, Tecnológico de Monterrey, verano de 1996.

DíAZ, R. "Oferta de mensajes televisivos extranjeros en Monterrey, N.L. y las preferencias programáticas de los jóvenes de secundaria". Tesis, Tecnológico de Monterrey, verano de 1995.

El Norte. (1993). "Regios prefieren ver el 'Canal de las Estrellas'". Página 8 E. 11 de marzo.

EstenNoU, J. (1990) "Crisis cultural y desnacionalización: la televisión mexicana y el debilitamiento de la identidad nacional". Comunicación y Sociedad, núm. 9, mayoagosto, pp. 97-121.

Greenberg y Buselle. (1993). "Gustos Jóvenes", Chasqui, núm. 46.

Hoskins, C., McFadyen, S. and Finn, A. (por publicar) "The environment in which cultural industries operate and some implications", en McAnany, E. G. y Wilkinson. Mass Media and Free Trade: NAFTA and the Cultural Industries, Austin, Texas: Texas Press.

LARSEN, P. (1990). Import/Export: International Flow of Television Fiction, UNESCO Reports and Papers on Mass Communication, núm. 104, Paris.

LozANO, J.C. (1994). "Recepción y uso de medios de comunicación en los jóvenes fronterizos", Anuario de Investigación de la Comunicación I, COEICC. México.

MalagamBA, A. (1986). "La televisión y su impacto en la población infantil de Tijuana", en Lozano, J.C. (1994) "Recepción y uso de medios de comunicación en los jóvenes fronterizos", Anuario de Investigación de la Comunicación I, coEICC. México.

MCANANY, E. y Wilkinson, K. (por publicar) "Free Trade and Cultural Industries in a NAFTA Era: An Introduction", en McAnany, E. G. y Wilkinson. Mass Media and Free Trade: NAFTA and the Cultural Industries, Austin, Texas: Texas Press. 
PooL, I. (1977) "The Changing Flow of Television". Joumal of Communication. Spring, pp. 139-149.

Rogers, E. y Antola, L. (1984) "Televisión en América Latina", Chasqui, núm. 9. Rogers, E. (1989) "Inquiry in Development Communication", en Asante, Molefi Kete. Handbook of International and Intercultural Communication, Newbury Park: Sage. SÁNCHEZ RUIZZ, E. (1992) "El espacio audiovisual mexiçano ante el Acuerdo de Libre Comercio Canadá-Estados Unidos-México", Comunicación y Sociedad., núms. 1415 , enero-agosto.

ScHRODER,K. (1993) "Can Denmark be Canadianized? On the Cultural Role of American TV-Serials in Denmark" en De la Garde, R, Gilsdorf, W. y Wechseimann, I. Small Nations, Big Neighbour, Denmark and Quebec/Canada compare notes on American popular culture, Academia Research Monograph 10.

SEPSTRUP, P. (1995). "Transnationalization of Television in Europe, a Study of Supply and Consumption in Five CountriesÓ. The Nordicom Review, núm. 1, pp. 1-5.

StraUbHaAR, J. (1993). "Más allá del imperialismo de los medios iricerdependencia asimétrica y proximidad cultural", Comunicación y Sociedad, núms. 18-19, mayo-diciembre, pp. 67-107.

VARIS, T. (1984). "The Intemational Flow of Television Programs", Journal of Communication, Winter, pp. 143-152.

Wilkinson, K. (1995). Where Culture, Language and Communication Converge: The Latin American Cultural Linguistic Television Market, Ph.D. diss., University of Texas, Austin. 